\title{
Emigrasjon som patologi - om Ørnulv Ødegårds studie av psykiske lidelser hos norske utvandrere til USA
}

\author{
Ved Arne Thorvik
}

\begin{abstract}
Den norske psykiateren Ørnulv Ødegård utga i 1932 avhandlingen Emigration and insanity, der han tar for seg den epidemiologiske forekomsten av psykiske lidelser hos norskfødte emigranter til delstaten Minnesota i USA. I denne artikkelen presenteres $\emptyset$ degårds historiske utgangspunkt, hans metode, samt de funn han gjorde og tilhørende forklaringsmodell. Videre inneholder artikkelen en retrospektiv drøfting av Ødegårds studie, og hans konklusjoner diskuteres i et vitenskapsideologisk perspektiv. - Suicidalitet drøftes bare kasuistisk i Ødegårds avhandling, og artikkelen avsluttes derfor med et supplerende avsnitt om emigrasjon og suicidrater.
\end{abstract}

Også det skrevne ord har sin begrensning som kunnskapsformidler, slår en amerikansk vitenskapshistoriker fast. Noe må erfares direkte, " be seen, touched and tasted" (Gould, 1981, s. 204).

Kanskje var det noe slikt den nyutdannede legen Ørnulv Ødegård (1901-1986) hadde i tankene, da han 3. desember 1927 gikk om bord i United States Lines' atlanterhavsdamper President Roosevelt i den franske byen Cherbourg. I "The New York Passenger List" for dette året kan man fortsatt lese at 26 år gamle "Ormilf Odegaard" var blant dem som 11 dager senere ankom metropolen. Det heter seg at han er "physician" av yrke, norsk av fødsel, men at han behersker engelsk språk (http:// www.ancestry.com).

For engelskkunnskaper var nødvendige for å gjennomføre forskningsprosjektet Ødegård hadde satt seg fore: $\AA$ studere den epidemiologiske forekomsten av psykiske lidelser hos nordmenn som hadde emigrert til USA. En tid arbeidet han ved Johns Hopkins University i Maryland (Retterst $\varnothing \mathrm{l}$ et al., 1980, s. 112). Sykehusets direkt $\varnothing \mathrm{r}$ var den sveitsiskf $\varnothing$ dte psykiateren Adolf Meyer (1866-1950), som ennå huskes som den som i 1905 hadde introdusert termen depresjon som erstatning for melankoli, og for sine studier av psykosers etiologi og forl $\varnothing \mathrm{p}$.

Imidlertid var det i delstaten Minnesota at Ødegård kom til å gjøre feltarbeidet for sitt prosjekt. Nettopp Minnesota hadde siden midten av 1800-tallet hatt en større kontingent norske immigranter. Her ble han tilknyttet Rochester State Hospital, et sykehus som hadde så vel urbant som ruralt nedslagsfelt, og som tok imot mennesker med alvorlige sinnslidelser til langtidsinnleggelser. Under veiledning av sykehusets direkt $\varnothing$ r Arthur Kilbourne var det at Ødegård utførte de nitidige studiene som kom til å resultere i den 206 sider lange monografien Emigration and insanity - A study of mental disease among the norwegianborn population of Minnesota, utgitt i København i 1932.

\section{Ødegårds utgangspunkt}

Som Ødegård selv nevner, er det av betydning å skissere den historiske konteksten som var tilgrunnliggende for at studien kom i stand.

Emigrasjon til USA hadde vært organisert i Norge helt siden 1825, da den 54 fot lange sluppen Restauration lyktes i å ta seg velberget over Atlanterhavet med 50 kvekere fra Rogaland om bord. Særlig kom skiftende konjunkturer i Norge på slutten av 1800-tallet til å stimulere til flere "utvandringsbølger". Nyere historikere har kalkulert at over 800000 mennesker dro til USA i tidsrommet 1825-1939, og at Norge i noen av utvandringsperiodene bare ble overgått av Irland når det gjaldt prosentandel som forlot hjemlandet (The National Archival Services of Norway, 2000; Nærbøvik, 1990, s. 22).

Selv om "Amerika" på denne måten ble en del av norsk dagligliv og kultur, kom norske myndigheter til å se på utvandringen med skepsis. Emigrantene var for en stor del menn i sin beste alder, som kunne ha gjort nytte for seg i arbeid og militærvesen. I noen grad ble de også latterliggjort. "Den fattigste stymper herover er greve", heter det i nidvisen Oleana om Ole Bulls (1810-1880) nybyggerprosjekt i Pennsylvania på 1850-tallet.

Derimot skal norske og europeiske myndigheter ha sett blidere på emigrasjon når det gjaldt mennesker som tydelig var mistilpassede, eller som Ødegård kaller "more or less defective individuals". "In its worst form this point of view led to the emigration of evident paupers, criminals, feebleminded and insane individuals with government support", skriver han (Ødegård, 1932, s. 188). Også fra amerikansk hold ble det etter hvert uttrykt slike synspunkter, men da med en bekymret undertone. "No people in the world are freer than we are from vicious inheritance", uttalte den profilerte psykiateren William Alanson White (1870-1937) i 1902, men gikk så over til å beskrive hvordan dette gode arvematerialet var truet av $\varnothing$ ket immigrasjon av europeisk "bunnfall" ("offscourings"). Flere studier indikerte at "foreign-born" var sterkt overrepresentert i amerikanske psykiatriske sykehus. I 1910 viste endog en undersøkelse at "next to the Irish the Scandinavians have the highest incidence of insanity of the various racial groups" (Ødegård, 1932, s. 28-34).

Også selvmordsrater blant immigranter ga grunn til bekymring. En studie tilsa at det var $\varnothing \mathrm{kt}$ forekomst av suicid hos nær sagt alle etniske grupper av "foreign-born inhabitants" i New York City i årene 1906 til 1914. Nordiske immigranter var intet unntak. I 1927 påviste en amerikansk lege at "Scandinavians" bare ble overgått av tyske immigranter når det gjaldt helsemyndighetenes rapporterte suicid i flere storbyer. "Scandinavian-born males also have extremely high rates", fastlo den amerikanske statistikeren Lous Dublin (1882-1969) og hans forskningsassistent i To be or not to be - A study of suicide, og viste samtidig til at selvmordsratene $\mathrm{i}$ Norge var lave, også i europeisk sammenheng (Dublin \& Bunzel, 1933, s. 32-36).

Amerikanske myndigheter kom derfor til å sette i gang tiltak for å forhindre at mennesker som ble ansett å ha utilstrekkelig psykisk eller fysisk helse, fikk adgang. $\varnothing$ degård nevner at man i New York hadde etablert en mottakskomité ("Board of Alienists") i 1904, som også bestod av tre psykiatere. Etter hvert kom komiteen til å ha fast tilhold på Ellis Island, som siden 1892 hadde fungert som mottaksstasjon. Enhver nyankommet ble her unders $\varnothing \mathrm{kt}$ av leger som vurderte fysisk og psykisk fungering, herunder evnenivå (Ødegård, 1932, s. 17-19). Immigrasjonssøkere som ikke innfridde medisinske krav, ble sendt tilbake til Europa (ofte til havnebyer i Nord-Frankrike, noe som førte til en offisiell protest fra franske leger i 1910 (Ødegård, 1932, s. 44)).

Den lille фya i New York Bay ble på denne måten de fleste norske emigranters 


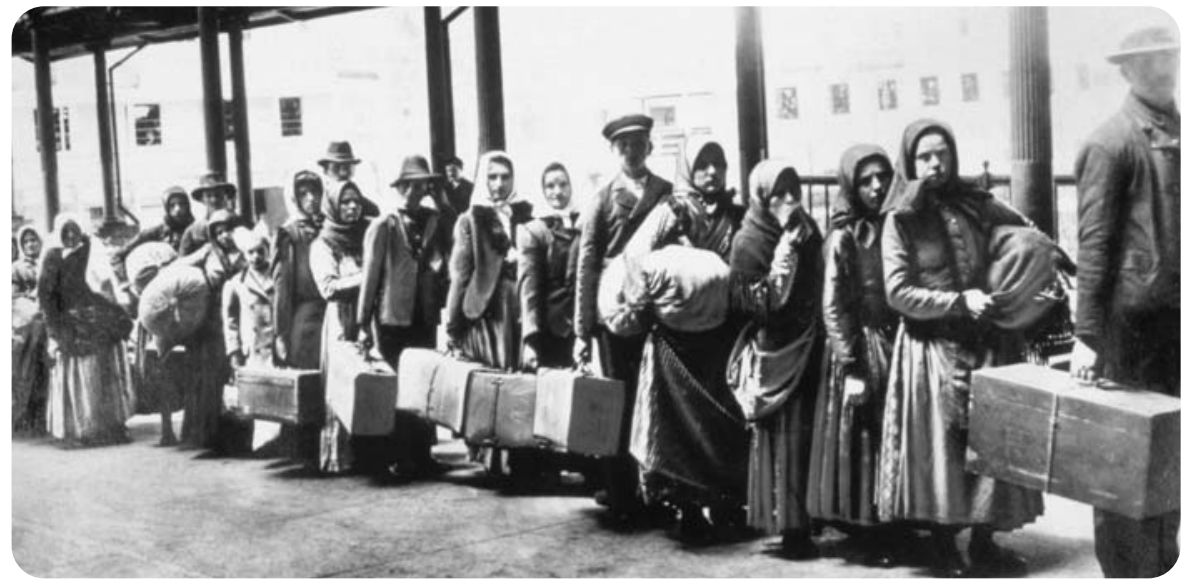

"The offscourings of Europe hasten to our shores" (dr. William A White, USA, 1902). Nyankomne emigranter, Ellis Island, New York, ca. 1900. Foto: Bettmann/CORBIS/Scanpix

første møte med "den nye verden". Noen ble hjemsendt av medisinske grunner. (Historikere har imidlertid pekt på at amerikanske myndigheter i mellomkrigstiden primært $\varnothing$ nsket å begrense immigrasjon fra $\$ \varnothing r-$ og $\varnothing$ st-Europa, og da med basis i samtidens raseteorier eller eugenikk. "The darker peoples of southern Europe and the Slavs of eastern Europe are less intelligent than the fair peoples of western and northern Europe", skrev en pioner innen intelligensmåling, Harvard-professoren Robert Yerkes (18761956) i 1922 (Gould, 1981, s. 197)).

I denne konteksten var det Ødegård gjorde sin forskning. Emigration and insanity skulle bli hans doktorgradsarbeid, og innledningen til en akademisk karriere.

\section{$\emptyset$ degårds metode}

Etter en innledende historikk presenterer $\varnothing$ degård presist sin problemstilling: Har norskf $\varnothing$ dte emigranter til USA i større grad anlegg for psykiske lidelser? Og hvilke følger har emigrasjon for psykisk helse?

I suicidologisk sammenheng er det viktig å være klar over at Ødegårds prosjekt var å studere psykisk helse generelt, og at han ikke spesifikt tar for seg suicid. I den grad suicid og suicidfors $\varnothing \mathrm{k}$ nevnes i Emigration and insanity, er det som en følgetilstand av alvorlig psykisk lidelse. Som vist senere, var det i datidens fagmiljøer alminnelig å se suicidalitet som direkte relatert til medisinske tilstander som depresjon eller psykose.

$\varnothing$ degårds metode er altoverveiende kvantitativ og statistisk. Primært tar han utgangspunkt i "Minnesota State Hospital Statistics", som gir tall på hvor mange norskfødte som har vært førstegangsinnlagt ved delstatens tre psykiatriske sykehus i perioden 1889-1928, og sammenligner så med tall gitt $i$ amerikansk folketelling (US Census) om norskfødte innbyggere i Minnesota. Eksempelvis angir US Census at det i tiåret 1919-1929 fantes 44262 norskfødte menn og 36593 norskf $\varnothing$ dte kvinner i delstaten (Ødegård, 1932, s. 65).

Tilsvarende gjør han en opptelling av førstegangsinnleggelser ved Gaustad sykehus for samme periode, altså de forutgående 40 år. Slik fremkommer harddata som kan ses i lys av norske folketellinger i Gaustads nedslagsfelt.

For å besvare sin problemstilling trenger Ødegård ikke bare å kjenne antallet førstegangsinnleggelser, men også den diagnostiske fordelingen av psykiske lidelser som førte til hospitalisering. Han er godt klar over at diagnostikk vil være farget av legens teoretiske ståsted. "Hardly two psychiatrists can be found who would agree in every case as to the differential diagnosis between "schizophrenia" and "manic-depressive insanity"'”. I en tid forut for manualer som DSM og ICD er hans løsning på problemet dette: Journaler fra så vel ett sykehus i Minnesota (Rochester) som ett i Norge (Gaustad) skal vurderes diagnostisk "by the same man", det vil si ham selv (Ødegård, 1932, s. 52). For perioden 1889-1928 leser han gjennom alle norskfødte pasienters journaler ved Rochester for så å sette diagnose, mens han ved Gaustad sykehus velger tilfeldig ut 50 journaler for hvert kalenderår for diagnostikk.
I Ødegårds arbeid inngår også 16 pasientkasuistikker, hvorav 13 er norskf $\varnothing$ dte pasienter som er innlagt i sykehus i Norge etter tilbakekomst. Flere av disse har gjort suicidfors $\varnothing \mathrm{k}$. Pasientenes forhistorie og erfaringer fra USA er grundig beskrevet, og avhandlingen har på denne måten også et kvalitativt element.

Et eget kapittel tar for seg fenomenet reemigrasjon, og er basert på tallmateriale fra Eg sykehus, som den norske legen Leif Melsom (1892-1968) presenterte i artikkelen Amerikaophold og sindssygdom (Melsom, 1924). Agderfylkene var godt egnet for denne typen studier. Først da overgangen fra seil til damp hadde ført til lavkonjunkturer mot slutten av 1800-tallet, hadde emigrasjonen kommet i gang for alvor fra sørlandsbyene, mens oppgangstider i Norge under første verdenskrig så hadde stimulert til reemigrasjon (Nærb $\varnothing$ vik, 1990, s. 27; Ødegård, 1932, s. 174).

\section{$\emptyset$ degårds funn}

Emigration and insanity er en omfattende studie, der mange diagnostiske undergrupper drøftes. Kort oppsummert kan funnene beskrives slik:

De norskf $\varnothing$ dte i Minnesota har betydelig flere førstegangsinnleggelser ved delstatens "state hospitals" enn $\varnothing$ vrig befolkning ("the natives"). Ødegård (1932, s. 70) antyder her en diskrepans på 30-50 \%. Videre tilsier hans materiale at det er schizofrene psykoser som i høy grad er tilgrunnliggende for denne overhyppigheten. Når man korrigerer for at emigranter for en stor del er i en aldersgruppe der schizofrene lidelser debuterer, kalkulerer Ødegård (1932, s. 198) en innleggelseshyppighet på 31,71/100 000 blant norskfødte i delstaten, mens det tilsvarende tallet i Gaustad sykehus' nedslagsfelt er 20,28/100 000 .

Den forhøyede innleggelseshyppigheten av pasienter med schizofreni blir av $\varnothing$ degård selv betegnet som studiens vesentligste funn (Ødegård, 1932, s. 194; Ådland, 1974). Videre tilsier hans materiale at "senile og arteriosklerotiske psykoser" har langt høyere forekomst og tidligere debut blant norskfødte i Minnesota enn hva tilfellet er i Norge. Når det gjelder affektive lidelser, finner Ødegård ingen signifikant forskjell. 


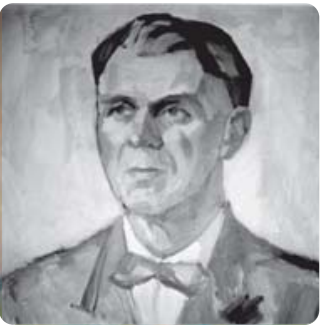

Ørnulv Ødegård (1901-86)

Endelig tilsier en kalkyle basert på Melsoms studie at det foreligger en fordoblet forekomst av sinnslidelser hos menn som har reemigrert, det vil si vendt tilbake fra USA. Kvinner var ikke tatt med i Melsoms tallmateriale. Derimot indikerer $\varnothing$ degårds studier at innleggelseshyppigheten har vært langt høyere for norskfødte kvinner i Minnesota enn i Norge (Ødegård, 1932, s. 87).

Som nevnt presenterer Ødegård også pasientkasuistikker, som altoverveiende tar for seg psykotiske lidelser hos emigranter, eller hos dem som har returnert til Norge etter USA-opphold. En kasuistikk ("No. 2") er illustrerende for hvordan Ødegård omtaler suicidfors $\varnothing \mathrm{k}$ og selvmutilering:

Pasienten ("B.G") er en 42 år gammel ugift mann, innlagt ved Rochester State Hospital, født i Norge. Han har bakgrunn i en velstående familie, der flere har utmerket seg innen forretningsliv og akademia, selv om det også er psykiske lidelser blant nærstående slektninger. Det heter seg at pasienten har gode intellektuelle evner, men alltid har vært sky og tilbaketrukket, og preget av "nerv $\varnothing$ sitet” og rastløshet. Fra 19-årsalder har han så to opphold i USA. Der han har lært seg godt engelsk, men bare hatt kortvarige arbeidsforhold. I perioder har han jobbet på en gård i Midtvesten som tilhører hans onkel, men blitt $\varnothing$ kende arbeidsufør grunnet somatiske plager, s $\varnothing v n$ vansker og tendens til "grubling". Forut for sykehusinnleggelsen fikk han også tanker om at noen fors $\varnothing$ kte å hypnotisere eller "påvirke" ham, og fors $\varnothing$ kte på et tidspunkt å knivstikke seg selv for å komme bort fra denne "påvirkningen". "He also tried to reach his brain through his ears with a nailfile to destroy the “influence"”, heter det i Ødegårds beskrivelse (Ødegård, 1932, s. 126-28).

\section{Ødegårds forklaringsmodell}

Ødegårds prosjekt er vel å merke ikke bare å unders $\varnothing$ ke hvorvidt det foreligger en overhyppighet av psykiske lidelser hos norskfødte immigranter i USA, og da spesifikt i Minnesota, men også å se egne funn i et etiologisk perspektiv. Hvordan skal den beskrevne overhyppigheten av schizofrene lidelser forklares? Er den relatert til den psykiske belastningen som selve utvandringen til et fremmed land må antas å være, eller finnes det en mer biologisk forankret forklaring?
I sin drøfting vektlegger Ødegård at han i materialet ikke har funnet noen tendens til at psykoser gir seg til kjenne kort tid etter ankomst til USA, slik man ville forvente ved en reaktiv tilstand. Tvert om har $75 \%$ av de norskfødte som innlegges i Minnesota med schizofrenidiagnose hatt et opphold på mer enn fem år i USA, og 54 \% i mer enn 10 år (Ødegård, 1932, s. 118). Videre har han i sin gjennomgang av journaler ved Rochester State Hospital bare funnet to pasienter der hjemlengsel ("homesickness") har vært anført, og et tilsvarende lite antall som har formidlet psykotisk tankeinnhold om hjemlandet (Ødegård, 1932, s. 120).

Med basis i denne empirien postulerer Ødegård en forklaringsmodell: Den beskrevne overhyppigheten er i alminnelighet ikke direkte relatert til den psykiske belastningen som emigrasjon medfører. Derimot har mennesker med konstitusjonelle anlegg for psykose vært overrepresentert blant emigrantene. Sett i lys av distinksjonen som den tyske psykiateren Ernst Kretschmer (1888-1964) laget mellom "schizoide" og "syntone" personer, vil nettopp de "schizoide" ha vansker med å tilpasse seg i arbeid og privatliv, og derfor tendere mot emigrasjon.

Om "the schizoid person" skriver Ødegård: "Friendless, defenceless and unpopular as they are, their peculiarities make them the victims of endless teasing and ridicule. Around the critical age of emigration (18 to 24) this attitude of opposition towards their surroundings is generally even more accentuated. Their home life is characterized by a strong opposition to their father or mother (...). Their teachers and employers find them difficult to get along with" (Ødegård, 1932, s. 108). - De "syntone" har imidlertid mer kunnet tilpasse seg i hjemlandet. Disse tenderer ifølge Kretschmers modell ikke mot psykoser, men mot affektive lidelser, som ifølge Ødegårds materiale ikke var overrepresentert hos norskfødte i Minnesota.

Som den refererte kasuistikken beskriver, kan slike "konstitusjonelle anlegg" også implisere suicidproblematikk. Det foreligger da en åpenbar psykotisk motivasjon for suicidalitet og alvorlig selvmutilering.

Når det gjelder den markante overhyppigheten av "senile og arteriosklerotiske psykoser", er hans forklaringsmodell mer nyansert. I noen grad kan overrepresentasjonen på "state hospitals" forklares ved at immigrantfamilier ikke har mulighet for å ta seg av sine eldre hjemme, som tilfellet er i Norge. Mer sannsynlig er det likevel at "the physical and mental strain of immigrant life" er etiologisk (Ødegård, 1932, s. 163).

Med hensyn til den relativt høye innleggelsesfrekvensen av norskfødte kvinner i Minnesota i de foregående 40 år, peker Ødegård ikke bare på "konstitusjonelle faktorer", men viser til at immigrantkvinner iallfall fram til forrige århundreskifte var prisgitt "the lonely life in poorly settled districts, which is probably felt more severely by the women who have to stay around the house most of the time" (Ødegård, 1932, s. 88).

\section{Diskusjon - 77 år etter}

Emigration and insanity er et sjeldent eksempel på at en doktoravhandling fra 1930-tallet fortsatt fascinerer. Selv om mye er endret, herunder at forskningsetikk tilsier at pasienter bør ha samtykket til at journalmateriale brukes i forskningsøyemed, fremstår monografien den dag i dag som solid og gjennomarbeidet. Nedenfor gjøres likevel et fors $\varnothing \mathrm{k}$ på å se Ødegårds arbeid i lys av definerte metodologiske variabler som reliabilitet, refleksivitet, validitet og relevans:

\section{Reliabilitet}

Umiddelbart virker det kvantitative elementet av studien reliabelt. Ødegård oppgir i detalj tallmaterialet som ligger til grunn for utregninger av varians og standardavvik, som er basis for hans påstand om $\varnothing$ ket innleggelseshyppighet blant norskfødte i Minnesota. Forfatterens reliabilitet styrkes også ved at han anfører mulige feilkilder, eksempelvis i delstatens statistikker over førstegangsinnleggelser. Videre gjør han rede for statistiske funn som umiddelbart ikke "passer inn" i egen forståelsesmodell, så som at det ikke lar seg påvise noen forskjell mellom "the schizophrenic and the affective cases" med hensyn til antall ugifte (Ødegård, 1932, s. 186). I en historisk kontekst der giftealder var lav, og giftemål i stor grad var å anse som et "nødvendig produksjonsfellesskap", ville man forvente et høyere antall ugifte blant de "konstitusjonelt mistilpassede" med schizofrene lidelser (noe Ødegård kom til å påvise i 
senere epidemiologiske studier i Norge (Retterst $\varnothing 1$ et al., 1980, s.26)).

Som vist problematiserer Ødegård det metodologisk vanskelige ved å lage en oversikt over den diagnostiske fordelingen i pasientmaterialet. Samsvarende med ettertidens paradigmeteoretikere synes $\varnothing$ degård å være på det rene med at observasjon er teoriladet, og velger som beskrevet en metode som tilsier at all diagnostikk utføres av en person med samme teoretiske utgangspunkt, ham selv. På dette punktet må reliabilitet ses i lys refleksivitet, altså at forskeren drøfter alternative forklaringsmodeller og egen forforståelse.

\section{Refleksivitet}

Det er tidligere nevnt at Ødegård skrev i en epoke forut for spesifiserte manualer som ICD og DSM. Hans utgangspunkt har vært klassifikasjonen som ble utarbeidet av den tyske psykiateren Emil Kraepelin (1856-1926) rundt forrige århundreskifte, og som i mellomkrigstiden ble videreført her i landet i den offisielle diagnoselisten (Medisinaldirektøren, 1928). Både for schizofrene og andre typer psykoser vektlegges da "de konstitusjonelle anlegg", noe som gjentas i forfatterskapet til den profilerte norske psykiateren Gabriel Langfeldt (1895-1983) (Langfeldt, 1954).

Ødegårds teoretiske utgangspunkt har altså vært en biologisk eller "konstitusjonell" modell. Det skal imidlertid nevnes at Ødegård drøfter alternative forklaringer på egne funn, eksempelvis hvorvidt det monotone prærielandskapet i delstaten kan virke psykosefremmende. At han i sin gjennomgang av journaler også har unders $\varnothing \mathrm{kt}$ om det rapporteres om hjemlengsel og psykotiske forestillinger om hjemlandet, kan vitne om at han i noen grad har latt seg influere av sitt studieopphold hos Adolf Meyer, hvis forfatterskap tradisjonelt har vært inkludert i psykodynamisk tradisjon (Arieti, 1955, s. 22). Jevnt over synes Ødegård å trekke konklusjoner med forsiktighet i studien.

I ettertid er det likevel slående at $\varnothing$ degård i langt større grad pretenderer å forklare overhyppigheten av schizofrene lidelser enn av "senile og arteriosklerotiske psykoser". For de førstnevnte st $\varnothing$ tter han seg til en spesifikk forklaringsmodell gitt av Kretschmer og andre av samtidens teoretikere. For de sistnevnte skriver han eksplisitt at man vet lite om "prepsychotic personality", og synes langt mer forbeholden når det gjelder å forklare egne funn (Ødegård, 1932, s. 155). I seg selv illustrerer dette moderne paradigmeteoretikeres understreking av samspillet mellom en teoretisk forforståelse og empiriske enkeltfunn, og at det "objektive" vitenskapsidealet Ødegård kom til å hevde i sitt senere forfatterskap neppe er realistisk (Kuhn, 1970; Ødegård, 1946, s. 9).

\section{Validitet}

I denne sammenhengen er drøfting av ekstern validitet særlig berettiget. Sagt på en annen måte: I hvilken grad er studiens funn overførbare utenfor den konteksten der forskningen ble foretatt?

Som Ødegård selv bemerker, er det en åpenbar innvending at studien som helhet er basert på data fremkommet i forbindelse med sykehusinnleggelser. At journaler ved Rochester State Hospital knapt beskrev hjemlengsel hos norskf $\varnothing$ dte førstegangsinnlagte, forhindrer ikke at emigranter ofte kan ha følt savn etter hjemstedet. Eksempelvis har dikteren Ingeborg Refling Hagen (1895-1989) fortalt at skildringer av en grå og ensom emigranttilværelse var tilgrunnliggende for diktsamlingen hun utga i 1932 med den betegnende tittelen Jeg vil hem att.

Når det gjelder Ødegårds sammenligning mellom innleggelsesrater i Minnesota og Norge, er det allerede nevnt at overrepresentasjonen av "senile og arteriosklerotiske psykoser" kan ses i lys av at immigrantfamiliene i mindre grad hadde mulighet for å pleie eldre familiemedlemmer hjemme enn hva tilfellet var i Norge. Også for dem med schizofrene lidelser kan lignende faktorer ha gjort seg gjeldende. "Even among the younger emigrants there are many rather lonely people without relatives or friends", skriver Ødegård (1932, s. 76).

\section{Relevans}

I en drøfting av studiens relevans er det verd å merke seg at Ødegård synes å anvende den påviste $\varnothing \mathrm{kte}$ innleggelsesraten til å hevde at "schizoide" personlighetstrekk forekommer hyppig hos emigranter generelt. "Norsk psykiater: Emigrantane var ofte rotlause opprørarar med anlegg for sinnsliding", lyder overskriften i et avisintervju Ødegård ga på 1970 tallet (Ådland, 1974). Det er vanskelig å se denne og tilsvarende formuleringer i Emigration and insanity som annet enn en overgeneralisering, tatt i betraktning at Ødegårds materiale i seg selv ikke tilsier annet enn at norskfødte innlegges cirka halvannen gang så hyppig i Minnesota enn i Norge for schizofrene lidelser (og da med ratio 31,71 pr 100 000, i en delstat som ifølge $\varnothing$ degårds eget materiale hadde rundt 80000 norskfødte på undersøkelsestidspunktet).

Det er her relevant å minne om at Ødegård gjorde sin studie i en historisk kontekst der emigrasjon ble ansett som uttrykk for mistilpassing og patologi. I tråd med tidens "mentalhygieniske" tankegang gir han i siste kapittel av Emigration and insanity konkrete råd om når og hvordan emigranter til USA skal tas hånd om og sendes hjem.

Etter den annen verdenskrig kom det offisielle Norges relasjon til USA til å endres dramatisk. USA var ikke lenger et tilfluktsted for mistilpassede, men vår viktigste allierte og samarbeidspartner. Mange vil huske NRKs reportasjer på 1960- og 70-tallet fra norske bosetninger i New York og Midtvesten. Emigrantskipet Restauration kaltes Den norske Mayflower, og 150-årsjubileet i 1975 ble markert med kongebes $\varnothing \mathrm{k}$ og myntutgivelse. Omtrent samtidig rullet filmatiseringen av Vilhelm Mobergs (1898-1973) romanserie Utvandrerne over TV-skjermene: Det unge ekteparet Karl Oskar og Kristina våger å sette kurs mot et ukjent land der de håper å kunne se resultater av sitt arbeid, mens den kristeligsinnede Danjel vil vekk fra et prestevelde som skor seg på brennevinssalg.

Den tyske filosofen Jürgen Habermas (1929-) har tematisert hvordan vitenskap står i et interaktivt forhold til politikk og den offentlige opinion (Habermas, 1974). Mens Ødegård beskriver emigrasjon som patologi, har utviklingen i etterkrigstiden implisert at nordmenns utvandring til USA har fått et heroisk anstrøk.

Det må likevel nevnes at Emigration and insanity kom til å ha stor betydning for norsk forskning innen psykiatrisk epidemiologi. Selv om metodikken har endret seg, og materialet er komplekst, er det også senere gjort studier som indikerer at psykiske og sosiale problemer i utgangspunktet kan være overrepresentert hos dem som endrer bosted (Dalgard, 2002). 


\section{Supplerende om suicidalitet}

Innledningsvis er det nevnt at amerikanske forskere i Ødegårds samtid hadde påvist en markant overhyppighet av suicid blant immigranter. Imidlertid drøfter ikke Ødegård denne problematikken. Derimot nevner han suicidfors $\varnothing \mathrm{k}$ kasuistisk, og da som del av symptombildet hos pasienter med psykotisk lidelse. I datidens fagmiljøer var det en utbredt oppfatning at suicidalitet alltid var knyttet opp mot definerte psykiske lidelser som depresjon eller psykose. Kraepelin hadde anslått at rundt $30 \%$ av dem som gjennomfører suicid var å anse som psykotiske (Retterstøl og Ekeberg, 2009). Dublin \& Bunzel beskriver i sin studie fra 1933 (s. 306) at også psykodynamisk orienterte leger tenderte mot at "only those afflicted with mental disease lack some strong attachment to an animate or inanimate object which keeps them from the negation of self-destruction".

Også i årene etter den annen verdenskrig ble en slik overhyppighet hos "foreign-born" påvist i USA, selv om denne ble mindre markant hvis man korrigerte for at immigranter ofte er i en aldersgruppe som ordinært har høyere suicidrate. Statistisk materiale ble etter hvert mer spesifisert, og "Scandinavians" delt inn i respektive nasjonaliteter. Det er verd å merke seg at statistikk for årene 1959-1961 viser en høyere suicidrate for svenskfødte enn for norskfødte immigranter til USA (33,1/100 000 mot 21,4/100 000 (Kramer et al., 1972, s. 187)). I denne perioden var suicidratene i Sverige (og Danmark) nær tre ganger så høye som i
Norge, og dette fenomenet ("The Scandinavian Suicide Phenomenon") ble i noen grad gjenspeilet i amerikanske statistikker.

Umiddelbart synes det altså å være slik at forskjeller i suicidrate blant spesifiserte folkegrupper lar seg påvise også etter emigrasjon, og senere statistikk fra flere land har i stor grad bekreftet at en slik "predisposisjon" foreligger. Både første og annen generasjons immigranter synes å ha forhøyet suicidrisiko. Tilsvarende hva Ødegård påviste når det gjaldt innleggelseshyppighet, tenderer særlig risiko å $\varnothing \mathrm{ke}$ hos kvinner. På noe sikt synes det imidlertid som om suicidrate hos emigrerte folkegrupper nærmer seg gjennomsnittlig suicidrate i tilflytningslandet. Denne typen konvergens impliserer at emigrasjon også kan medføre et fall i suicidrate, dersom aktuelle folkegruppe emigrerer fra et opphavsland med høy rate til et tilflytningsland med lavere rate. Eksempelvis er dette påvist for danske immigranter i Canada i perioden 1969-73 (Kliewer, 1991).

I seg selv illustrerer dette kompleksiteten i det suicidologiske fagfelt. Vel er det slik at suicidrate er relatert til forekomst av definerte psykiske lidelser, der Ødegårds hypotese om "konstitusjonelle anlegg" hos emigranter kan ha relevans. Det kan i den forbindelse nevnes at norske suicidrater falt suksessivt gjennom annen halvdel av 1800-tallet (Halbwachs, 1930/1978, s. 257), noe som hypotetisk kan ha sammenheng med at mennesker med suicidrisiko var overrepresentert blant dem som utvandret. At suicidrater over tid konvergerer mot gjennomsnittlig rate i tilflytningslandet, kan imidlertid vanskelig tolkes på annen

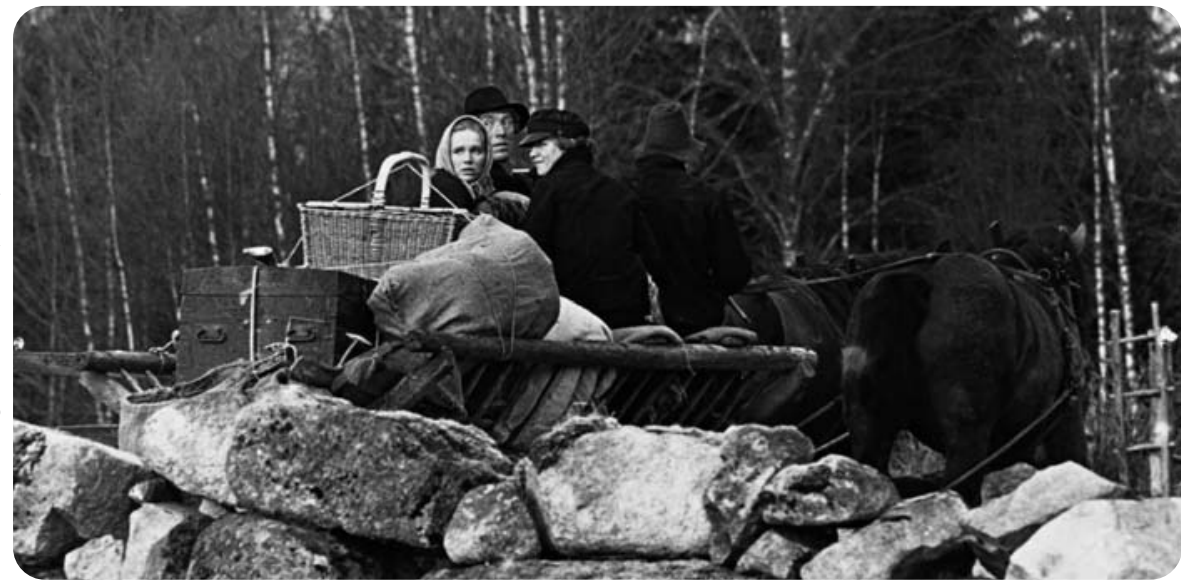

Emigrasjon som heroisk handling. Liv Ullmann, Max von Sydow og Eddie Axell i filmatiseringen av Vilhelm Mobergs "Utvandrerne" (Jan Troell 1971) måte enn at suicid som fenomen er influert av kulturelle og miljømessige faktorer. $\varnothing$ ket suicidrate blant første og annen generasjons immigranter blir i så fall også å forstå som uttrykk for den påkjenningen som skifte av bosted, kultur og språk kan innebære, eller sagt med en formulering fra Ødegårds Emigration and insanity: "the physical and mental strain of immigrant life".

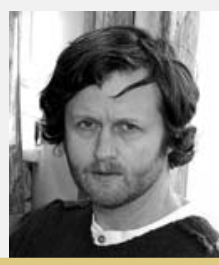

Arne Thorvik er psykiater og ansatt i Psykiatrien i Vestfold, og arbeider også med et forskningsprosjekt om håp hos suicidale pasienter. Han er redaksjonell medarbeider i Suicidologi.

\section{Referanser}

Arieti, S. (1955). Interpretation of schizophrenia. New York: Robert Brunner.

Dalgard, O.S. (2002). Psykiatrisk epidemiologi i Norge - et historisk tilbakeblikk. Norsk Epidemiologi, 12 (3), 163-172.

Dublin, L., \& Bunzel, B. (1933). To be or not to be A study of suicide. New York: Harrison Smith and Robert Haas.

Gould, S.J. (1981). The mismeasure of man. New York: Norton \& Company.

Habermas, J. (1974). Vitenskap som ideologi. Oslo: Gyldendal.

Halbwachs, M. (1978). The causes of suicide. London: Routledge. (Utkom første gang i 1930)

Kliewer, E. (1991). Immigrant suicide in Australia, Canada, England and Wales, and the United States. Journal of the Australian Population Association, 8 (2), 111-128.

Kramer, M., Pollack., E.S., Redick, R.W., \& Locke, B.Z. (1972). Mental disorders/Suicide. Cambridge, Massachusetts: Harvard University Press.

Kuhn, T.S. (1970). The structure of scientific revolution (2nd edition, enlarged). Chicago: The University of Chicago Press.

Langfeldt, G. (1954). Lærebok i klinisk psykiatri. Oslo: Aschehoug.

Medisinaldirektøren. (1928). Sinnssykeasylenes virksomhet. Oslo: Aschehoug.

Melsom, L. (1924). Amerikaophold og sindssygdom. Med. revue, vol. 24

The National Archival Services of Norway. (2000). The Norwegian emigration - 175 years. Bergen: The Digital Archives. Lest 20.11.2009.

http://digitalarkivet.uib.no/utstilling/eng/main.htm

Nærbøvik, J. (1990). Norsk historie 1870-1905. Oslo: Samlaget.

Retterstøl, N., Dahl, A.A., \& Astrup, C. (red). (1980). Gaustad sykehus 125 år. Oslo: Universitetsforlaget.

Retterst $\varnothing 1$, N., \& Ekeberg, Ø. (2009). Christianity and suicide. I: D Wasserman \& C Wasserman (red): The Oxford Textbook of Suicidology and Suicide Prevention. Oxford: Oxford University Press.

Ødegård, Ø. (1932). Emigration and insanity - A study of mental disease among the norwegian-born population of Minnesota. Copenhagen: Levin \& Munksgaards Publishers.

Ødegård, Ø. (1946). Nazisme og mentalhygiene. Oslo: Aschehoug.

Ådland, E. (1974, 8. februar). Intervju med Ørnulv $\emptyset$ degård. Dag og Tid. 